\title{
Effects of applied voltage on the phase constitution and corrosion behaviors of micro-arc Ti6Al4V coating
}

\author{
Zhang Yunlong $^{1}$, Li Changqing ${ }^{2 \star}$, Zhang Yumin ${ }^{3}$, Wang Shucheng ${ }^{2}$, Zhou \\ Yufeng $^{3}$
}

${ }^{1}$ College of Materials science and engineering, Jiamusi University, 154007, China

${ }^{2}$ Colloge of Materials Sicence and Engineering, Heilongjiang University of Science and Technology, China,150022

${ }^{3}$ Center for Composite Materials and structure, Harbin Institute of Technology, Harbin, China 150080

aylzhdr@126.com, 'llchangqing@163.com, czhym@hit.edu.cn, dwangshchlx@126.com, e'zhouyf@hit.edu.cn

Keywords: Micro-arc oxidation coatings, Ti6Al4V alloy, Corrosion resistance

\begin{abstract}
The in-situ ceramics coating were fabricated by the micro-arc oxidation technology in order to improve the corrosion resistance of Ti6Al4V alloy. The silicate electrolyte system was introduced to reduce the applied voltage of the MAO coating. The influence of applied voltage on phase composition, surface morphology and dynamic polarization behavior was investigated. The addition of applied voltage make the MAO pore bigger and quantity of MAO pore reduced. The introduce of MAO coating on the surface of Ti6Al4V alloy improved corrosion resistant performance.
\end{abstract}

\section{Introduction}

Titanium alloys were very attractive materials for a number of engineering applications due to their low density and high static and dynamic strengths as well as good corrosion resistance. Ti6Al4V alloy, which was mostly used in the aerospace, marine and biomedical industries. Ti6Al4V began to lose its popularity after recognition of toxicity arising from in-vivo release of vanadium present in the composition. Titanium based implants exhibited different trends to some degree when their surface topography and composition were changed by appropriate surface modification techniques $^{[1-3]}$. The MAO technology was widely used in aviation and marine industries due to its special technological features and had become an important method to improve the corrosion and wear resistance of light alloys such as $\mathrm{Al}$ and $\mathrm{Mg}$, et al. Compared with coating made by traditional anodic oxide methods, the film by MAO was much thicker and harder and attaches to the substrate more firmly. Furthermore, most of the existing literature focused on the structure and composition of ceramic coating ${ }^{[4,5]}$. However research on some specitial electrolytic system were relatively rare. Based on above consideration, we investigated the effect of the applied potential on the phase composition and surface morphologiesof the Ti6Al4V MAO coating. The other objective of the present study was to characterize the corrosion behavior of the Ti6Al4V MAO coating in the $\mathrm{NaCl}$ solution.

\section{Materials and method}

The commercial Ti6Al4V plate was cut into the $10 \mathrm{~mm} \times 10 \mathrm{~mm} \times 2 \mathrm{~mm}$ as substrate. The TC4 alloy specimen and the wall of the stainless steel container were used as the anode and cathode, respectively. A solution including $\mathrm{Na} 2 \mathrm{SiO} 3, \mathrm{NaOH}, \mathrm{KF}$ and EDTA-2Na was applied as basic electrolyte solution with $\mathrm{pH}$ value of $11 \sim 12$. The micro arc oxidation coating deposition process was kept in $10 \mathrm{~min}$. The electrolyte temperature was controlled within $25^{\circ} \mathrm{C} \sim 30^{\circ} \mathrm{C}$. The additives composed of Na2SiO3(25g/L), $\mathrm{NaOH}(12 \mathrm{~g} / \mathrm{L}), \mathrm{KF}(4 \mathrm{~g} / \mathrm{L})$ and EDTA-2Na (4g/L) were mixxed into basic electrolyte solution. The above solution were configurated to evaluate their effects on the 
MAO coating. The voltage was varied from $240 \mathrm{~V}$ to $360 \mathrm{~V}$ with the interval of $30 \mathrm{~V}$ and the specimen was designed as S240, S270, S300,S330 and S360, espectively. The frequency and duty of the DC field were $500 \mathrm{~Hz}$ and $10 \%$. Each sample was oxidized for $10 \mathrm{~min}$ and then cleaned ultrasonically in acetone and de-ionized water before further analysis. The phases of five group specimens were evaluated by $\mathrm{X}$-ray diffraction using $\mathrm{Cu}_{\mathrm{k}}$ radiation, between $15^{\circ}$ and $85^{\circ}$ with increments of $0.02^{\circ}$. Microstructure of the specimens was observed by a scanning electron microscope (S-4700, Hitachi). The chemical composition of the layer was analyzed with an energy dispersion spectroscope at an acceleration voltage of $300 \mathrm{kV}$. Surface roughness was measured by a self focusing laser microscope. The corrosion resistances of various specimens were investigated by a potential dynamic polarization technique on an electrochemical workstation. The tests were performed in a $\mathrm{NaCl}$ solution at $37^{\circ} \mathrm{C}$ in a cell with three electrodes, a platinum plate as the counter electrode and a saturated calomel electrode as the reference electrode. The treated Ti6Al4V alloy specimens were used as working electrodes, the sample area exposed being $1 \mathrm{~cm}^{2}$. Tests were performed at a scanning rate of $0.5 \mathrm{mV} / \mathrm{s}$ and starting from $100 \mathrm{mV}$ below open circuit potential and were stopped when a potential of $1500 \mathrm{mV}$ was reached.

\section{Results and discussion}

\section{Phase composition of the MAO coating}

The phase composition of MAO coating was determined by XRD pattern and the results were depicted in Fig.1. As shown in Fig.1, the $\mathrm{TiO}_{2}$ MAO coating was composed of rutile and anatase phases. With the increase of the applied voltage, some Ti and diffraction peaks of anatase type $\mathrm{TiO}_{2}$ disappeared and more diffraction peaks of rutile- $\mathrm{TiO}_{2}$ emerged. As the applied voltage increased, the intensity of the diffraction peaks of rutile type $\mathrm{TiO}_{2}$ became stronger and the intensity of the diffraction peaks of anatase type $\mathrm{TiO}_{2}$ and $\mathrm{Ti}$ turned weaker gradually. The diffraction peaks at 36.94 ${ }^{\circ}$, 53.89॰ and $55.06^{\circ}$ was corresponding respectively to the (103), (105), and (211) planes of anatase type $\mathrm{TiO}_{2}$ phase.

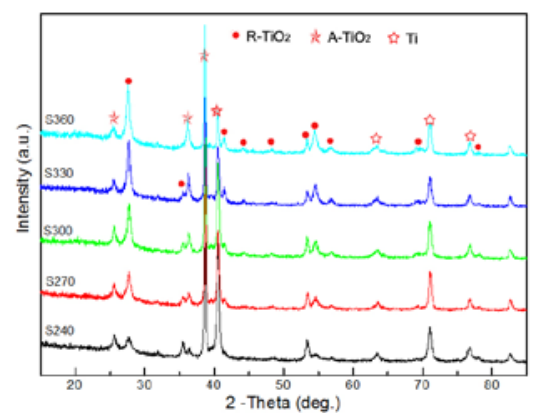

Fig.1 XRD spectra of MAO films of the Ti6Al4V in different applied voltage.

A new diffraction peak of rutile $\mathrm{TiO}_{2}$ phase was detected when the diffraction peaks was $54.32 \circ, 39.19^{\circ}$ and $56.64 \circ$ was found as rutile $\mathrm{TiO}_{2}$ phase, which was corresponding to the (211), (200) and (220) plane. The above results indicated that the increase of the applied voltage would lead to crystallization of the $\mathrm{MAO} \mathrm{TiO}_{2}$ coating and the anatase phase of $\mathrm{TiO}_{2}$ phase was converted into the rutile type $\mathrm{TiO}_{2}$ phase in the MAO ceramics coatings.

\section{Surface Morphology of oxide MAO coating}

The surface morphology of TC4 MAO coating with different applied voltage were listed in Fig.2. The pore dimensions increased and the quantity reduced as applied voltage increased. When applied voltage was less than $270 \mathrm{~V}$, the average diameter of the MAO pore was less than $0.4 \mu \mathrm{m}$. Meanwhile, the pore size was uniform and coating surface was smoother. When applied voltage was beyond $270 \mathrm{~V}$, coating surface became coarse. So the smooth degree of micro arc oxidation coating can be controlled by the introduce of appropriate applied voltage. As indicated by the EDX spectra shown in Fig.2f), compared with Ti6Al4V substrate, some additional elements (such as O, $\mathrm{Si}, \mathrm{Al}, \mathrm{Ti}$ and $\mathrm{K}$ ) were detected in the Ti6Al4V MAO ceramics coating, in which Si and K elements came from the electrolyte and $\mathrm{O}$ probably presented in $\mathrm{TiO} 2$ which was formed in the process of micro-arc oxidation. The addition of the KF was responsible for the decline of applied voltage 
during the MAO process.

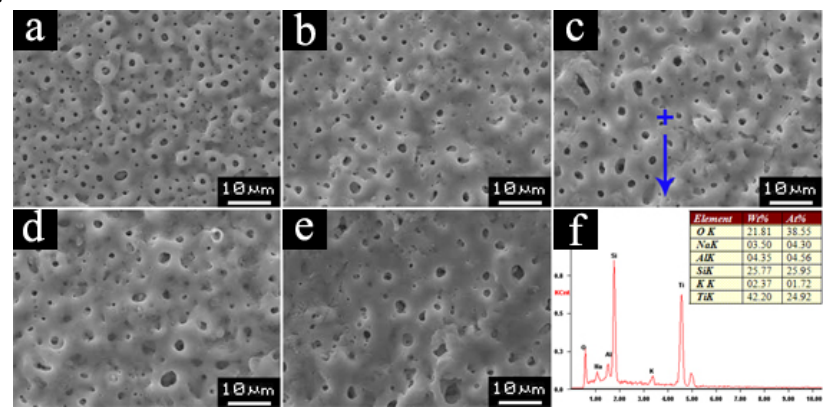

Fig.2 Surface morphologies of Ti6Al4V MAO coating prepared in different applied voltage. a) e) represented applied voltage $240 \mathrm{~V}, 270 \mathrm{~V}, 300 \mathrm{~V}, 330 \mathrm{~V}$ and $360 \mathrm{~V}$.

The three-dimensional shape of the Ti6Al4V MAO ceramics coating was recited in Fig.3. a), b) and c) represented applied voltage $240 \mathrm{~V}, 300 \mathrm{~V}$ and $360 \mathrm{~V}$. As showed in Fig.3, there was no obvious difference for the depth of MAO pore of Ti6Al4V alloy even if applied voltage was different.

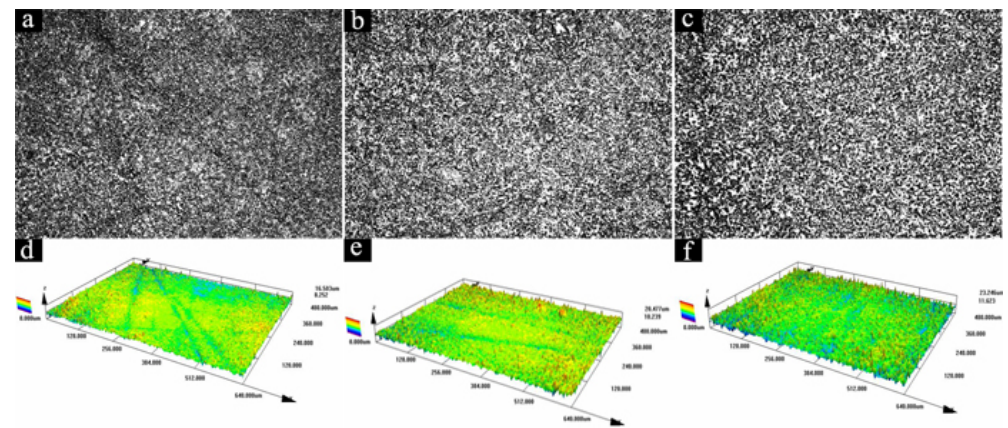

Fig.3 morphologies of Ti6Al4V MAO coating prepared in different applied voltage.

\section{Corrosion resistance of oxide coating}

The anodic potentio-dynamic polarisation curves of different specimens under different prepared potential was showed in Fig.6. The corrosion potential of all the MAO treated specimens was higher than that of the substrates and corrosion potential of S240,S270, S300,S32 and S360 was about $-0.376 \mathrm{~V},-0.399 \mathrm{~V},-0.409 \mathrm{~V},-0.441 \mathrm{~V}$ and $-0.475 \mathrm{~V}$. At the same time, the their corrosion current densities were lower than the matrix materials, which of S240, S270, S300, S32 and S360 was closed to $2.7 \times 10^{-5} \mathrm{~A}, 3.89 \times 10^{-5} \mathrm{~A}, 4.38 \times 10^{-5} \mathrm{~A}, 7.06 \times 10^{-5} \mathrm{~A}$ and $1.03 \times 10^{-4} \mathrm{~A}$. So it can be said that the corrosion resistance of $\mathrm{Ti6Al4V}$ in the $\mathrm{NaCl}$ solution had clearly improved after the MAO treatment. The oxide film increased the chemical stability of the specimen and it made corrosion potential shift positively. Therefore, applied voltage was very important for fabricating MAO coating with good corrosion resistance.

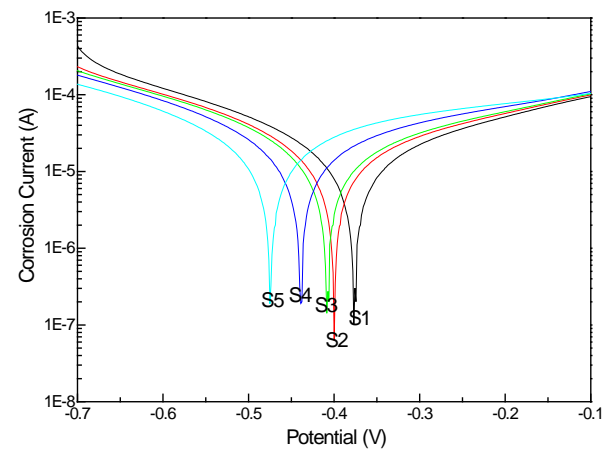

Fig.4 The anodic potentio-dynamic polarisation curves of different applied voltage.

\section{Conclusion}

In this paper, $\mathrm{TiO}_{2} \mathrm{MAO}$ coating with rough surface were fabricated successfully by micro arc oxidation technology. The effect of the applied voltage on the phase composition, surface 
morphology and dynamic polarization behavior of the $\mathrm{TiO}_{2} \mathrm{MAO}$ coating was investigated. The increase of applied voltage led to crystallization of $\mathrm{TiO}_{2}$ coating and anatase type $\mathrm{TiO}_{2}$ phase was converted into rutile type $\mathrm{TiO}_{2}$ phase. The addition of the KF was responsible for the decline of applied voltage during the MAO process. The ceramics coating was mainly consisted of rutile-TiO2 and anatase-TiO2 phase.

\section{Acknowledgements}

The authors were grateful for the support by the science and technology research project of education department of Heilongjiang Province (No.12531586). The Major State Basic Research Development Program (No.2014CB46505) and The science and technology innovation team of Jiamusi university(No.Cxtd-2013-03).

\section{References}

[1] Fu L, Ying S, Fu P W, et al. Formation characterization of hydroxyapatite on titanium by micro-arc oxidation and hydrothermal treatment. Journal of Bioscience and Bioengineering, 2005, 100: 100-104.

[2] Zhang Y X, Han Y, Huang P, et al. Adhesive strength and bioactivity of titania films prepared by micro arc oxidation. Journal of the Chinese Ceramic Society, 2004, 32: 122-126.

[3] Wei D Q, Zhou Y, Jia D C, et al. Effect of applied voltage on the structure of micro arc oxidized $\mathrm{TiO}_{2}$-based bioceramic films. Materials Chemistry and Physics, 2007, 104: 177-182.

[4] Li L H, Kong Y M, Kim H W, et al. Improved biological performance of Ti implants due to modification by micro-arc oxidation. Biomaterial, 2004, 25: 2867-2875.

[5] Wang Q L, Ge S R, Shi X L, et al. Structure and property of micro-arc oxidation ceramic layer on titanium alloy. Journal of China University of Mining \& Technology, 2008, 37: 462-466. 